\title{
Comparison of Dexmedetomidine and Dexamethasone as Adjuvant to Bupivacaine in Supraclavicular Brachial Plexus Block
}

\author{
Saadia Khaleeq, ${ }^{1}$ Muhammad Azam, ${ }^{2}$ Sana Siddiq, ${ }^{3}$ Adeel Shahid, ${ }^{4}$ Zulqarnain Butt, ${ }^{5}$ Naila Asad 6
}

1,23,4,6Department of Anesthesia SIMS/Services Hospital, Lahore-Pakistan, ${ }^{5}$ Department of Anesthesia, Avicenna Medical College, Lahore-Pakistan

\begin{abstract}
Objective: Brachial plexus block is one of the commonly used anesthetic technique for upper limb procedures in orthopedics. A number of drugs have been used as adjuvants to local anesthetic agents, to prolong the duration and enhance the quality of the block. Some of these are clonidine, dexmedetomidine, ketamine, dexamethasone and magnesium sulfate. We conducted this study to evaluate dexmedetomidine and dexamethasone with respect to the onset and duration of sensorimotor block. Their effects on hemodynamic parameters as well as duration of analgesia after surgery were also recorded. Study Design: Prospective Randomized controlled design. Settings: Anesthesia, ICU and pain management department of Services Hospital/SIMS, Lahore Pakistan. Duration: From 15th September 2019 till 15th March 2020. Methodology: Sixty patients fulfilling the inclusion criteria were enrolled in the study after taking informed written consent for upper limb procedures under supraclavicular brachial plexus block. These patients were divided into two groups BD and BG with 30 patients in each group. Patients in Group BD received $32 \mathrm{ml}$ of $0.375 \%$ bupivacaine $(30 \mathrm{ml})$ with 100 microgram of dexmedetomidine $(2 \mathrm{ml})$. Group BG patients received $32 \mathrm{ml}$ of $0.375 \%$ bupivacaine $(30 \mathrm{ml})$ with $8 \mathrm{mg}$ of dexamethasone $(2 \mathrm{ml})$. The onset and duration of sensory and motor block, time to request for first rescue analgesic and hemodynamic changes in both groups of patients were recorded. Results: The results of our study revealed that the patients in group BD had earlier onset and longer duration of sensory and motor block with minimal hemodynamic changes. Conclusion: Dexmedetomidine is superior to dexamethasone as an adjuvant, in terms of rapid onset and prolonged duration of sensorimotor block and postoperative analgesia after supraclavicular block, with minimal hemodynamic changes.
\end{abstract}

Keywords: Supraclavicular brachial plexus block, Bupivacaine, Dexmedetomidine, Dexamethasone.

Corresponding Author

Submitted for Publication: 25-03-2020

Dr. Saadia Khaleeq, Assistant Professor of Anesthesia, SIMS/Services Hospital Lahore-Pakistan

Email: saadia.raza64@gmail.com

Citation: Khaleeq S, Azam M, Siddiq S, Shahid A, Butt Z, Asad N. Comparison of Dexmedetomidine and Dexamethasone as Adjuvant to Bupivacaine in Supraclavicular Brachial Plexus Block. APMC 2020;14(2):122-5.

\section{DOI: 10.29054/APMC/2020.889}

\section{INTRODUCTION}

The introduction of safer techniques has tremendously increased the popularity of peripheral nerve blocks in recent years leading to frequent use of these for anesthesia and postoperative analgesia. Those patients who are considered unfit for general anesthesia can be anesthetized without hesitation due to the availability of newer techniques to perform nerve blocks. ${ }^{1}$ Upper extremity orthopedic procedures can be safely done under brachial plexus block without general anesthesia. Brachial plexus block, when performed through supraclavicular approach, provides consistent, reliable and uniform anesthesia. It adds to the quality of postoperative pain relief and patient satisfaction. ${ }^{2}$

Bupivacaine is the most commonly used local anesthetic agent in our set up because of its free availability and longer duration of action. However, it has some disadvantages like slow onset, patchy effect and the potential to cause systemic toxicity due to possible intravascular injection of a large dose. ${ }^{3}$

Different drugs have been used as perineural adjuvants to local anesthetics in an attempt to enhance the quality and duration of single shot nerve blocks. ${ }^{4}$ The glucocorticoid dexamethasone, is well known for its anti-inflammatory as well as analgesic properties. ${ }^{5}$ These properties are due to blockade of nociceptive $\mathrm{C}$ fibers and phospholipid $A^{2} \cdot{ }^{6}$ Although its role as a perineural adjuvant is well recognized elsewhere, such studies are sparse in Pakistan. ${ }^{7}$ Dexmedetomidine, a drug recently introduced in our country, is being increasingly used in intravenous regional anesthesia, procedural sedation and analgesia in ICU setting. It is also known to improve the quality of central neuraxial blocks. In recent years, it has been used as an adjuvant to local anesthetics while performing peripheral nerve blocks. . $^{8,9} \mathrm{We}$ designed this study to compare the effectiveness of the two drugs as an adjuvant to $0.375 \%$ bupivacaine for supraclavicular brachial plexus block, to choose the better one for routine practice of regional anesthesia in our setup.

\section{METHODOLOGY}

Study Design: Prospective Randomized Controlled design. Settings: Anesthesia, ICU and pain management department of Services Hospital/SIMS, Lahore Pakistan.

Duration: Six months from September 15, 2019 to March 14 2020.

Data Collection Procedure: After the approval by Institutional Ethical Review Board and obtaining informed consent, sixty patients were included in this trial. Patients with preexisting neurological deficit, diabetes mellitus, abnormal ECG, taking steroids and allergic to study drugs were excluded. Patients were divided into two groups, BD and BG, randomly by 
computer generated number. Each group comprised of 30 patients.

Group BD patients received $0.375 \%$ bupivacaine $30 \mathrm{ml}+100 \mu \mathrm{g}$ of dexmedetomidine $(2 \mathrm{ml})$.

Group BG patients received $0.375 \%$ bupivacaine $30 \mathrm{ml}+8 \mathrm{mg}$ dexamethasone $(2 \mathrm{ml})$

On arrival of the patient, an intravenous line was secured in the non-operated arm and maintained with a crystalloid infusion. Baseline vital signs and $\mathrm{SpO} 2$ were recorded. All necessary resuscitation equipment including $20 \%$ intralipid, was kept ready for any possible local anesthetic toxicity. Patient was asked to lie supine with head turned to opposite side. Injection midazolam $2 \mathrm{mg}$ was given for sedation. Under strict aseptic conditions, injection lignocaine was used to anaesthetize the skin at a point approximately $2 \mathrm{~cm}$ cephalad to the middle of the clavicle. A 22-gauge $5 \mathrm{~cm}$ insulated needle (B Braun) was used with a nerve stimulator. The current intensity was set initially to 2 milliampere. The drug volume was injected in small increments, once the desired motor response was obtained at a current of 0.4-0. 5 milliampere.

After injection, patients were checked for beginning of sensory block using pinprick sensation in

C2- T2 dermatomal region and graded as follows;

$0=$ feeling sharp pinprick (no block)

$1=$ blunt sensation on pinprick (partial block)

$2=$ no sensation on pinprick (complete block).

Onset of sensory blockade was taken as time from injection of drug until complete loss of pinprick sensation (score 2). Duration of sensory blockade was time duration between complete sensory block (score 2) to complete recovery of sensations in the blocked dermatomes (score 0 ).

Motor blockade was assessed by modified Bromage scale.

$0=$ normal muscle function with full range of movement of elbow, wrist and fingers.

$1=$ Decreased muscle power so that patient can move fingers and /or wrist only.

$2=$ Complete loss of muscle function with no movement in fingers/wrist.

Onset of motor block was the time between injection of drug to complete loss of muscle power (score 2). Duration of motor block was time interval from complete motor block (score 2) to complete recovery of function of hand and forearm muscles (score 0).

Duration of analgesia in next 24 hours was recorded according to VAS that is visual analogue scale $(0-10)$ for measuring intensity of pain. When VAS became more than 4 , time was noted and nalbuphine $0.1 \mathrm{mg} / \mathrm{kg}$ was given as rescue analgesic. Other complications of supraclavicular block such as pneumothorax, vascular injury and systemic toxicity to local anesthetic were recorded if there were any.

Statistical Analysis: Data was analyzed on SPSS 24. Demographic data was expressed as mean \pm SD. Time of onset, duration of surgery and motor block and time to request for first rescue analgesic was compared by independent sample t- test. $A$ value of $P<0.05$ was considered significant.
RESULTS

The two study groups were comparable in terms of demographic data without significant statistical difference (Table1).

Table 1: Demographic data

\begin{tabular}{|c|c|c|}
\hline & $\begin{array}{c}\text { Dexmedetomidine } \\
\text { (Group BD) (Mean } \pm \text { SD) }\end{array}$ & $\begin{array}{c}\text { Dexamethasone } \\
\text { (Group BG) (Mean } \pm \text { SD) }\end{array}$ \\
\hline Age & $40.77 \pm 14.52$ & $39.57 \pm 11.97$ \\
\hline $\begin{array}{c}\text { Gender } \\
\text { (M:F) }\end{array}$ & $15: 15$ & $17: 13$ \\
\hline
\end{tabular}

The difference between two groups regarding onset time and duration of sensory block was statistically significant $(p=0.000)$. The onset time of motor block also showed significant difference between the groups $(p=0.001)$. The duration of motor block was significantly prolonged in Group BD $(p=0.000)$. The time to request for first rescue analgesic was significantly increased in Group BD ( $p=0.001)$. Table 2 .

Table 2: Efficacy of dexmedetomidine and dexamethasone

\begin{tabular}{|c|c|c|c|c|}
\hline \multicolumn{2}{|c|}{} & $\begin{array}{c}\text { Dexmedetomidine } \\
\text { (Group BD) } \\
\text { (Mean } \pm \text { SD) }\end{array}$ & $\begin{array}{c}\text { Dexamethasone } \\
\text { (Group BG) } \\
\text { (Mean } \pm \text { SD) }\end{array}$ & $\begin{array}{c}\text { P } \\
\text { value }\end{array}$ \\
\hline \multirow{2}{*}{$\begin{array}{c}\text { Sensory } \\
\text { Block }\end{array}$} & $\begin{array}{c}\text { Onset } \\
\text { (min) }\end{array}$ & $19.5 \pm 4.2$ & $23.5 \pm 3.7$ & 0.000 \\
\cline { 2 - 5 } & $\begin{array}{c}\text { Duration } \\
\text { (min) }\end{array}$ & $876 \pm 236.12$ & $659.6 \pm 177.2$ & 0.000 \\
\hline Motor & $\begin{array}{c}\text { Onset } \\
\text { (min) }\end{array}$ & $30.67 \pm 3.88$ & $34 \pm 3.80$ & 0.001 \\
\cline { 2 - 5 } Block & $\begin{array}{c}\text { Duration } \\
\text { (min) }\end{array}$ & $773.33 \pm 198.23$ & $564 \pm 153.27$ & 0.000 \\
\hline \multicolumn{2}{|c|}{$\begin{array}{c}\text { Time to request for } \\
\text { first rescue } \\
\text { Analgesic (min) }\end{array}$} & $1015.5 \pm 245.98$ & $807.5 \pm 196.74$ & 0.001 \\
\hline
\end{tabular}

No nausea or vomiting was observed in either of the two groups. Bradycardia was observed in only 3 patients in group BD versus 2 patients in group BG which was not significant $(p=0.64)$. Change in baseline blood pressure was not statistically significant $(p=0.55)$.

Table 3: Side effects of dexmedetomidine and dexamethasone

\begin{tabular}{|c|c|c|c|c|c|}
\hline \multicolumn{2}{|c|}{ Side Effects } & $\begin{array}{c}\text { Patients Receiving } \\
\text { Dexmedetomidine } \\
\text { (BD) }\end{array}$ & $\begin{array}{c}\text { Patients } \\
\text { Receiving } \\
\text { Dexamethasone } \\
\text { (BG) }\end{array}$ & $\begin{array}{c}\text { Total } \\
\text { (N) }\end{array}$ & $\begin{array}{c}\text { P } \\
\text { value }\end{array}$ \\
\hline \multirow{2}{*}{ Bradycardia } & Yes & 3 & 2 & 5 & 0.64 \\
\cline { 2 - 7 } & No & 27 & 28 & 55 & \\
\hline \multirow{2}{*}{ Hypotension } & Yes & 1 & 2 & 0 & 0.55 \\
\cline { 2 - 7 } & No & 29 & 28 & 60 & \\
\hline \multirow{2}{*}{$\begin{array}{c}\text { Nauseal } \\
\text { Vomiting }\end{array}$} & Yes & 0 & 0 & 0 & \\
\cline { 2 - 7 } & No & 30 & 30 & 60 & \\
\hline
\end{tabular}




\section{DISCUSSION}

Regional anesthesia in orthopedic procedures is superior to general anesthesia in terms of better postoperative pain relief, less central nervous system depressant effect of drugs and early discharge from hospital. ${ }^{10}$

Brachial plexus block is a convenient and commonly used regional anesthetic technique for upper limb surgical procedures. Although different approaches are available but we selected supraclavicular approach as it is a simple and safe technique for anesthesia and analgesia for surgeries below the shoulder joint. ${ }^{11}$ In these blocks various drugs like clonidine, buprenorphine, ketamine and dexmedetomidine have been used as adjuvants to local anesthetic drugs to speed up the onset, prolong the duration and improve the quality of block.12 Dexmedetomidine has been used as perineural adjuvant to local anesthetic drugs in different regional and peripheral nerve blocks and has been proven to be an excellent choice in potentiating local anesthetic effect.

The current study has shown that dexmedetomidine when used as an adjuvant to bupivacaine in supraclavicular brachial plexus block, leads to rapid onset and significantly longer duration of sensory and motor blockade as compared to dexamethasone $(p=0.000)$. Duration of analgesia after surgery was also prolonged in patients receiving dexmedetomidine $(p=0.001)$. Moreover, no significant hemodynamic changes were observed.

El-Sayed et al (2019) compared dexamethasone and dexmedetomidine as adjuvants to bupivacaine in infraorbital block for cleft lip repair. They observed a significantly lower postoperative FLACC pain scale (face, legs, activity, cry and Consolability scoring for pediatric analgesia) and a longer time to first analgesic request that is 690 minutes with dexmedetomidine as compared to 546 minutes with dexamethasone. ${ }^{13}$ These results were quite similar to our findings.

Hamda et al (2019) in a study with these same drugs for supraclavicular block, found that dexmedetomidine has more profound inhibitory effect on unmyelinated $\mathrm{C}$ fibers for pain than A alpha motor fibers. ${ }^{14}$ We also concluded that dexmedetomidine causes longer duration of sensory block as compared to motor blockade.

Another study conducted by Wei et al (2018) showed that addition of dexmedetomidine to ropivacaine caused rapid onset and prolonged duration of sensory as well as motor blockade when compared with ropivacaine alone They also noted that dexmedetomidine did not cause any significant hemodynamic changes irrespective of the dosage used. Their results are quite consistent with our findings.

In their study Karanam et al (2017) comparing two doses of dexmedetomidine (50 and 100 micrograms) as adjuvants to bupivacaine in supraclavicular block observed a significantly early onset of sensory $(p=0.026)$ and motor block $(p=0.032)$ with 100 microgram dexmedetomidine. Although the incidence of bradycardia was higher with this dose $(p=0.009)$, hypotension recorded was not statistically significant $(p=0.056) .{ }^{16}$ In our patients, 100 microgram dexmedetomidine did not cause significant hypotension $(p=0.64)$ or bradycardia $(p=0.55)$.

Another study with the findings consistent our study results was conducted by Arun et al (2018). They compared duration of sensory and motor blockade and postoperative analgesia after axillary block with dexmedetomidine and dexamethasone as adjuvants to bupivacaine. They found that the duration of sensory and motor blockade and postoperative analgesia was significantly more in dexmedetomidine group $(p<0.001) .{ }^{17}$

Another study conducted by Lee et al (2016), compared the effect of dexmedetomidine 100 microgram and dexamethasone $10 \mathrm{mg}$ as local anesthetic adjuvants and local anesthetic alone in axillary brachial plexus block. Contradictory to our results, they did not find significant difference among the effect of adjuvants dexmedetomidine and dexamethasone when added to local anesthetic ( $p$ value $>0.05$ ). ${ }^{18}$ This effect may be due to increased dose of dexamethasone $(10 \mathrm{mg})$ in their study. We used only $8 \mathrm{mg}$ of dexamethasone.

Aliste $J$ and coworkers (2019) compared perineural dexamethasone and dexmedetomidine for infraclavicular block. They concluded that dexamethasone used as an adjuvant results in better sensorimotor blockade and analgesic duration $(p<0.001) .{ }^{19}$ Their findings were different from our results. This could be due to increased total volume $(35 \mathrm{ml})$ used in their study while we used only $32 \mathrm{ml}$.

\section{CONCLUSION}

In the light of the above, we conclude that dexmedetomidine is a better choice as an adjuvant to local anesthetics to enhance the quality and duration of nerve block without significant cardiovascular changes.

\section{LIMITATIONS}

Our study was limited in that we included only ASA I and ASA II (physical status according to American Society of Anesthesiologists) patients. We also might have missed any delayed complications due to the block as the patients were not followed beyond 24 hours postoperatively.

\section{SUGGESTIONS / RECOMMENDATIONS}

In future more studies can be done with different doses of dexmedetomidine and in patients with comorbidities.

\section{CONFLICT OF INTEREST / DISCLOSURE}

None.

\section{ACKNOWLEDGEMENTS}

We acknowledge the full support and guidance provided to us by Professor Naila Asad and Dr. Mohammed Ashfaque.

\section{REFERENCES}

1. Kaur M, Lakhani A, Hashia A M. Comparative study between dexamethasone and dexmedetomidine in supraclavicular block. Int J Adv Med. 2018;(1):57-61. 
2. Modh DB, Parmar M, Solanki S. Effect of dexmedetomidine as adjuvant in supraclavicular block for upper limb Orthopedic surgeries. Int. Surg. 2017;4(5):1510-15.

3. Krishan G, Mitra S, Verma A P, Agrawal M, Singh R P, Ahmad S. A comparative study between levobupivacaine with dexmedetomidine versus levobupivacine with clonidine in ultrasound guided supraclavicular brachial plexus block for upper limb surgeries: A randomized double-blind placebo-controlled study. IJCMR. 2018;5(1):6-11.

4. Vorobeichik L, Brull R, Abdallah FW. Evidence basis for using perineural dexmedetomidine to enhance the quality of brachial plexus nerve blocks: a systemic review and meta-analysis of randomized controlled trials. BJA. 2017;18(2):167-81.

5. Verma N K, Ranjan A. A clinical comparison of dexmedetomidine and dexamethasone as adjuvant to ropivacaine in supraclavicular brachial plexus blocks for upper arm surgeries. Int J Adv Res Biol Sci. 2016;3(7):56-61.

6. Golwala M, Swaida VN, Dhemair AA, Sridhar NV. Pain relief by Dexamethasone as an adjuvant to local anesthetic in supraclavicular brachial plexus block. Anaesth Clin Pharmacol. 2009;25(3):285-8.

7. Arish BT, Babu DD, Lazarus SP, Chandar DD, Balasubramanian $\mathrm{S}$, Kumar K S. Effect of dexamethasone as an adjuvant to local anesthetic in supraclavicular brachial plexus block. Int J Sci Stud. 2016;3(10):147-53.

8. Agarwal S, Aggarwal R, Gupta P. Dexmedetomidine prolongs the effect of bupivacaine in supraclavicular brachial plexus block. J Anesthesiol Clin Pharmacol. 2014;30(1):36-40.

9. Ping $Y, Y e Q$, Wang $W, Y e P$, You Z. Dexmedetomidine as an adjuvant to local anesthetics in brachial plexus blocks. Medicine. 2017;96(4):1-8.

10. Abdallah $F$ W,Brull $R$. Facilitatory effects of perineural dexmedetomidine on neraxial and peripheral nerve block: a systematic review and meta-analysis. British Journal of Anaesthesia.2013;110 (6): 915-25.

11. Meena R, Loha S, Pandey A R, Meena K, Paswan A K, Chaudhary L. Dexmedetomidine as an adjuvant to Bupivacaine in Supraclavicular Brachial Plexus Block. J Anesth Clin Res. 2016;7(674):1000674

12. Sivakumar S, Rajarajeswaren K. Use of dexmedetomidine or buprenorphine along with bupivacaine for ultrasound guided brachial plexus block: a comparative randomized prospective study. JMSCR.2016;4(6):10802-6.

13. El-Emam E M, Enas A. A Comparative Evaluation of Dexamethasone and Dexmedetomidine as adjuvants for Bupivacaine in Ultrasound -Guided Infraorbital Nerve Block for cleft lip repair: A Prospective, Randomized, Double -Blind Study. Anesth Essays Res. 2019;13(2):354-8.

14. Hamda M H, Ibrahim W M E, Ashiry M A. Comparative study between Dexmedetomidine and Dexamethasone as an adjuvant to Bupivacaine in ultrasound guided supraclavicular brachial plexus block in upper limb surgeries. Egypt $J$ Hosp. 2019;75(6):3060-9.

15. Wei MM, Maocai MM, et al. The effect and safety of Dexmedetomidine added to Ropivacaine in brachial plexus block: A meta-analysis of randomized controlled trials. Medicine (Baltimore). 2019:97(14):e12573.

16. Nallam $S R$, Chiruvella $S$, Karanam $S$. Supraclavicular brachial plexus block:Comparison of varying doses of demedetomidine combined with levobupivacaine. Indian $J$ Anaesth. 2017;61(3):256-261.

17. Gunaseelan S, Kumar A J. Comparison of motor blockade, sensory blockade and duration of analgesia between dexmedetomidine and dexamethasone as an adjuvant to bupivacaine in axillary block: Indian Journal of Clinical Anaesthesia. 2018;5(3):437-9.

18. Lee MJ, Koo DJ, Choi YS, Lee KC. Dexamethasone or Dexmedetomidine as local anesthetic adjuvants for ultrasound guided axillary brachial plexus blocks with nerve stimulation. Korean J Pain. 2016;29(1):29-33.

19. Aliste J, Layera S, Bravo D et al. Randomized comparison between perineural dexamethasone and dexmedetomidine for ultrasound guided infraclavicular block: Reg Anesth Pain Med. 2019:11.

\section{AUTHORSHIP CONTRIBUTION}

Saadia Khaleeq

Muhammad Azam

Sana Siddiq

Adeel Shahid

Zulqarnain Butt

Naila Asad
Basic concept \& design of work Interpretation \& analysis of data Data collection \& data analysis Data collection \& final drafting Data collection \& data analysis Data analysis \& discussion writing 